\title{
PEMBERTON'S ACETABULOPLASTY FOR CONGENITAL DISLOCATION OR SUBLUXATION OF THE HIP
}

\author{
A. L. EYRE-BROOK, D. ANTHONY JONES, F. C. HARRIS \\ From the Winford Orthopaedic Hospital and the Royal Hospital for Sick Children, Bristol
}

\begin{abstract}
The results obtained in a consecutive series of thirty-seven Pemberton operations for congenital dislocation or subluxation of the hip are reported. Over the period under review, 1967 to 1973, it was the only type of acetabuloplasty employed at Winford. Unless the mandatory concentric reduction could be obtained with ease, preliminary open reduction was favoured, especially in cases of primary care. Femoral rotation osteotomy was added for marked anteversion. The programme was designed to be complete inside fourteen weeks, and was so for eighteen hips. Secondary acetabuloplasty was performed on hips with instability or dislocation persisting despite previous treatment. The operations were performed from eighteen months to thirteen years of age. One initial failure required a repeat operation which was successful, but one severely dysplastic hip remained so. The average follow-up was six years.
\end{abstract}

The pericapsular acetabuloplasty described by Pemberton in 1965 is unique in that the antero-medial cortex of the ilium is divided above the acetabulum as well as the antero-lateral cortex, so that the ilium has to be exposed subperiosteally on both sides (Fig. 1). In younger children with the hip concentrically reduced and with the triradiate cartilage still present, the double cut permits the whole extent of the roof of the acetabulum to descend and cover the femoral head both medially and laterally. This paper sets out to record the results obtained in a consecutive series of such operations (Fig. 2), performed on thirty-seven hips by one surgeon (E.B.) on both favourable and unfavourable cases, and followed up for an average of six years (Fig. 3), admittedly a rather short period.

\section{REDUCTION OF A DISLOCATED HIP}

To quote Trevor, Johns and Fixsen (1975), "Concentric reduction of the femoral head is essential if acetabuloplasty is to maintain stability". This has certainly been

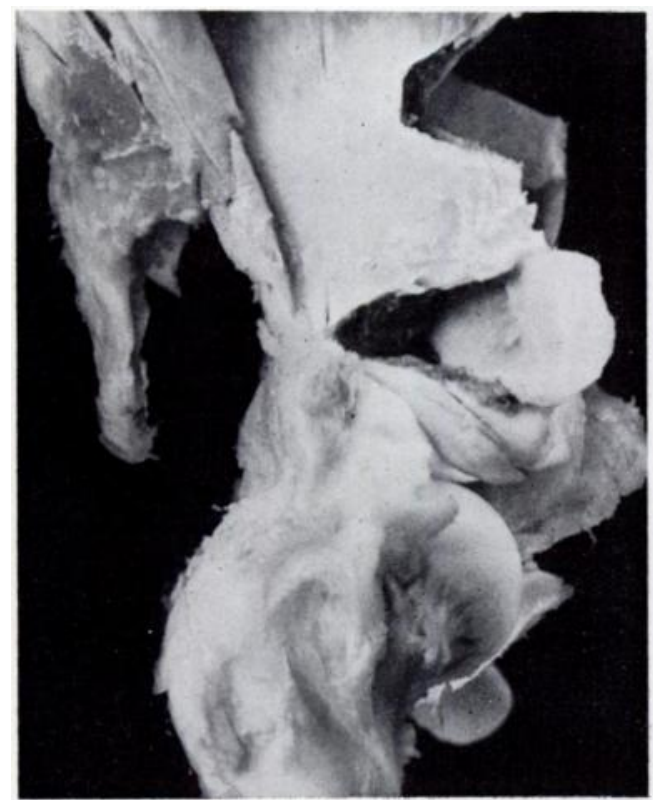
The antero-lateral and antero-medial aspects of the dissected pelvis of a normal child
of Pemberton's operation on the right hip.

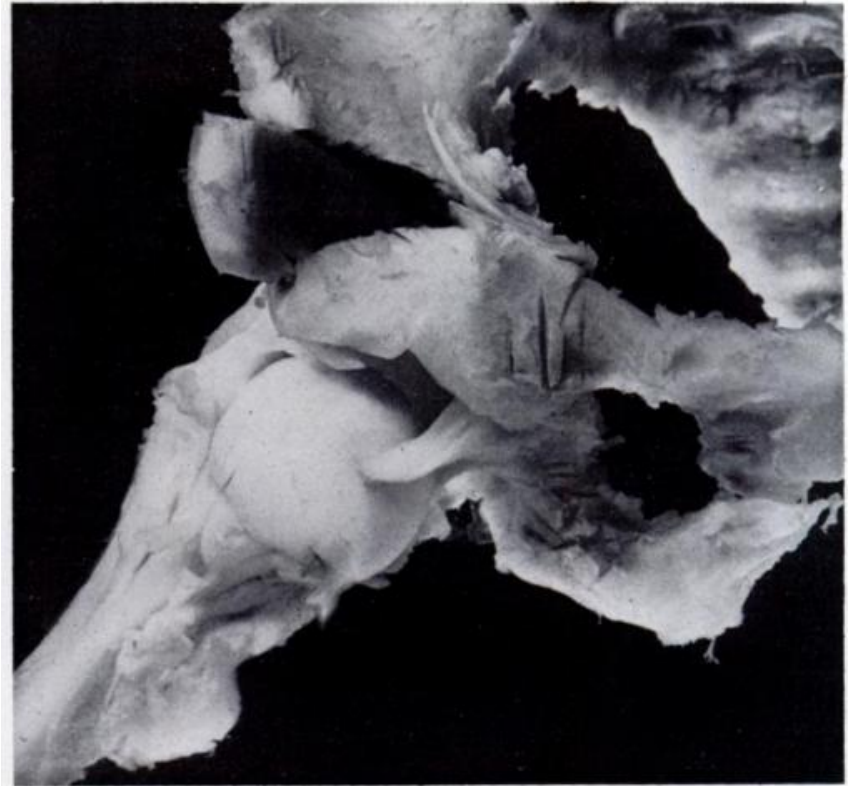

Fig. 1

A. L. Eyre-Brook, M.S., F.R.C.S., 8 Lodge Drive, Long Ashton, Bristol BS18 9JF, England.

D. Anthony Jones, B.Sc., F.R.C.S., Consultant Orthopaedic Surgeon, Morriston Hospital, Swansea, Wales.

F. C. Harris, F.R.C.S., 12 Hickory Street, Brandon, Manitoba, Canada, RMB 022. 
our experience, and for this reason we have frequently performed open reduction either before or at the time of acetabuloplasty. Thus in this series, of eighteen hips presenting for primary treatment, sixteen had open reduction. The point can hardly be over-stressed.

Closed reduction. After a period of simple skin traction in most children, the hip was examined very gently under an anaesthetic. Concentric reduction was considered to have been attained when it was felt that considerable stability had resulted and the radiograph confirmed that the head was in the acetabulum. Only such favourable cases had immobilisation in plaster. Other- femoral head, and the virtual absence of epiphysitis in this series is confirmatory. In most hips not previously treated, the femoral head showed some degree of medial flattening and some reduction in the antero-posterior dimension, but the cartilage was smooth and glistening. This contrasted markedly with the findings in many secondary cases, where the femoral head, mutilated by prolonged localised pressure, showed areas of fibrillation or loss of cartilage and distortion; indeed one, perched on the rim of the acetabulum, was bilobular. The case for almost routine open reduction appeared completely convincing, provided it was done by a surgeon experienced in this field.

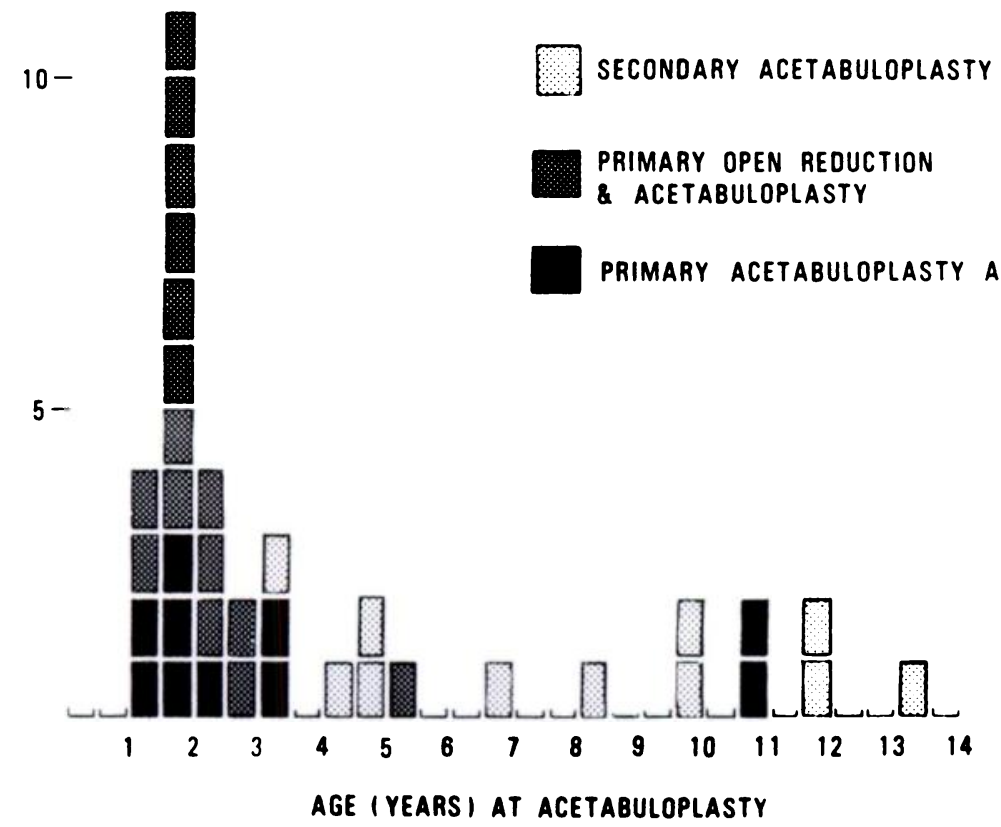

Fig. 2
$10-$

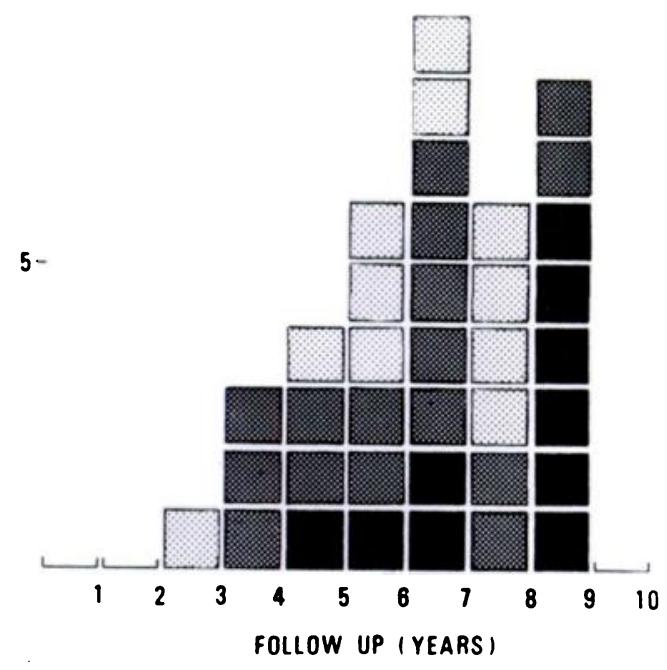

Fig. 3

Figure 2-A histogram showing the age at the time of Pemberton's operation on thirty-seven hips. Figure 3-A histogram showing the interval between operation and review.

wise, and in all cases of doubt, open operation was infinitely preferred to running the risk of severe damage from localised pressure due to imperfect reduction.

When concentric reduction was not obtained with ease, the hip was left quite free until open reduction was performed. In infancy this was delayed until nine months. In the interval no treatment whatsoever was given, because any so-called "bloodless method" is a risk to the delicate femoral head.

Open reduction. Open operation, frequently performed in this series, has confirmed the obstacles to closed reduction-mainly the shortened medial capsule overlain by a tight psoas tendon, a much enlarged ligamentum teres, and occasionally a labrum enlarged enough to require reduction in size. In all cases the ligamentum teres was excised, but with no bleeding from the femoral end, which was severed first. This upholds the view that in these dislocated hips the ligamentum teres provides no appreciable blood supply to the

\section{STABILISATION OF A CONCENTRICALLY REDUCED HIP JOINT}

The aim in the primary cases was to obtain concentric reduction, to fashion a stable roof to the acetabulum, and if necessary to correct excessive anteversion of the femoral neck - all in a single short programme of some fourteen weeks.

In many primary cases the open operation gave an opportunity to assess anteversion, which, if over 30 degrees, was corrected by rotation osteotomy with plate fixation. This was performed on eleven of the sixteen hips but never at the time of open reduction and primary acetabuloplasty, because control of reduction could be lost should the plate fixation-never strong in an infant-fail. Under those circumstances osteotomy was performed three to six weeks later, extending the time in a plaster spica from the usual six to eight weeks to ten to fourteen weeks. No special treatment was given after removal of the plaster spica. 


\section{TECHNIQUE OF OPEN REDUCTION AND ACETABULOPLASTY}

This description differs little from that given by Pemberton but adds some important points gained from our own experience.

Open reduction. The incision for the Smith-Petersen approach starts about 2 centimetres below the anterior half of the crest; this leaves a better scar. The lateral cutaneous nerve is preserved. The capsule is exposed in the usual way and the muscles attached to the outer cortex of the ilium are elevated subperiosteally. At this point it is important to cut the periosteum, not only anteriorly down to the antero-inferior spine but also just above the capsule, so that a quadrilateral of periosteum and muscle, hinged posteriorly, can be adequately retracted to give an excellent view of the superior capsule. The

Table I. Classification of the thirty-seven Pemberton operations

\begin{tabular}{|c|c|c|}
\hline & Average age & Number \\
\hline $\begin{array}{l}\text { Primary acetabuloplasty } \\
\text { (a) With open reduction } \\
\text { (b) Without open reduction } \\
\text { (i) after closed reduction } \\
\text { of dislocation } \\
\text { (ii) with subluxation only }\end{array}$ & $\begin{array}{l}2 \text { years } \\
\text { (one hip at } 6 \text { years } \\
\text { excluded) } \\
2 \text { years } \\
21 / 2 \text { years } \\
\text { (two hips at } 11 \\
\text { years, } R \text { and } L \text {, } \\
\text { excluded) }\end{array}$ & $\begin{array}{l}16 \\
2 \\
8\end{array}$ \\
\hline $\begin{array}{l}\text { Secondary acetabuloplasty } \\
\text { (a) Unstable hips from our own } \\
\text { clinic, previously treated by } \\
\text { reduction (open 1, closed 2) } \\
\text { and rotation osteotomy } \\
\text { (b) Hips from other clinics } \\
\text { (i) open reduction and } \\
\text { acetabuloplasty now } \\
\text { repeated } \\
\text { (ii) Pemberton's operation } \\
\text { only }\end{array}$ & $\begin{array}{l}9 \text { years } \\
4 \text { years } \\
10 \text { years }\end{array}$ & $\begin{array}{r}3 \\
5 \\
11\end{array}$ \\
\hline
\end{tabular}

cartilaginous epiphysis of the iliac crest is then split horizontally from the antero-superior spine backwards; the free portion is displaced medially, and by cutting laterally over the medial metaphysial surface of the crest, the periosteum is divided along this line and is stripped from the inner surface of the ilium together with iliacus. The medial periosteum also needs to be cut anteriorly and along the antero-medial margin of the acetabulum to enable it to be well retracted, giving a good exposure of the anterior capsule. The tendon of rectus femoris is usually cut obliquely at this stage and can later be sutured with lengthening.

The tendon of psoas, lying in the posterior fibres of iliacus, is frequently divided and allowed to retract within the iliacus. If it is to be lengthened, the line of oblique division must be fully 4 centimetres in length because full inward rotation of the reduced hip displaces the lesser trochanter far backwards, particularly when anteversion is marked.

The capsule is now opened by a curved incision based antero-superiorly to give a generous flap attached to the acetabulum above and in front. This is most important because full inward rotation of the limb carries the capsule attached to the femoral neck well posteriorly, where it may become useless for later capsular repair and leave a defect anteriorly.
The femoral head is now turned out and the ligamentum teres cut flush; no bleeding comes from this end. The proximal end of the ligament is then detached. Attempts to remove the fat pad always result in much bleeding; being soft and compressible, it can be left in situ. The prominent labrum is left intact except when greatly enlarged, as it was in only three cases in this-series. Reduction is still blocked by the tight medial capsule, even after section of the psoas tendon, and it needs liberal section. Reduction is now easy, the femoral head passing beneath the enlarged labrum. It is essential to get rid of the false acetabular pouch by peeling off the capsule from its attachment to the outer surface of the ilium, usually by sharp dissection.

Concentric reduction having been obtained, the cavity formerly housing the femoral head obliterated and the anteversion recorded, we can, if necessary, proceed to reconstruction of the acetabulum. This is called for when the reduction has little stability with the leg in the neutral position, and particularly when the acetabular roof is not cupped well over the femoral head.

Pemberton's acetabuloplasty. First a triangle of bone is cut, based on the crest and of appropriate height. The outer and inner aspects of the acetabulum are next well presented by the use of two Trethowan bone levers, each passed subperiosteally into the greater sciatic notch. We prefer a 5 millimetre straight osteotome to cut the cortex 6 millimetres above the acetabular margin, starting through the upper portion of the anterior inferior iliac spine and passing laterally and medially up to the edges of the retracted glutei and ilio-psoas respectively. When the part of the osteotomy beneath these muscles has to be made, a curved 6 millimetre osteotome is directed along a line judged to be half-way between the margin of the acetabulum and the greater sciatic notch, and designed to reach the horizontal limbs of the triradiate cartilage. The cancellous bone between the cortical cuts is cleft with a 25 millimetre curved osteotome. This requires no hammering; the osteotome enters easily and levers the roof down gently. In younger children lowering of the whole roof occurs by a fracture-separation at the triradiate cartilage, with immediate moulding over the femoral head.

The osteotomy can be opened up to 4 centimetres in older children; 1.5 centimetres has been found adequate in most younger children, but it is preferable to err on the generous side. The osteotomy shows a marked tendency to close spontaneously from a springy action. A groove on each cancellous surface is created, and a spinal spreader is introduced laterally to hold the osteotomy open, allowing the triangular wedge of bone to be placed centrally and vertically. Both cortices of the graft resist closure as well as the basal epiphysial element. No wedge has slipped in this series. The acetabuloplasty is better done in the reduced position of the hip, though the femoral head can be readily reduced without imperilling the reconstruction. The capsule is now cut away where excessive and is carefully sutured anteriorly and superiorly.

The closure of the Smith-Petersen exposure is routine. With the hip in moderate abduction and medial rotation, a spica is applied down to the ankle on the affected side with the knee flexed 20 degrees, and down to the knee on the other side. It is retained for six to eight weeks according to age.

Femoral rotation osteotomy. When an osteotomy is required for anteversion exceeding 30 degrees, this is performed three to six weeks after the acetabuloplasty and extends the time spent in plaster by six to eight weeks.

Rotation osteotomy was performed in twenty-three out of the whole series of thirty-seven hips. At review all twenty-three retained a range of lateral rotation at least as great as the range of medial rotation. No osteotomy has had to be repeated-the altered range of movement has persisted.

\section{CLINICAL MATERIAL}

The thirty-seven Pemberton operations have been classified as shown in Table I. The ratio of bilateral to unilateral cases was twelve to nineteen, but only six of 

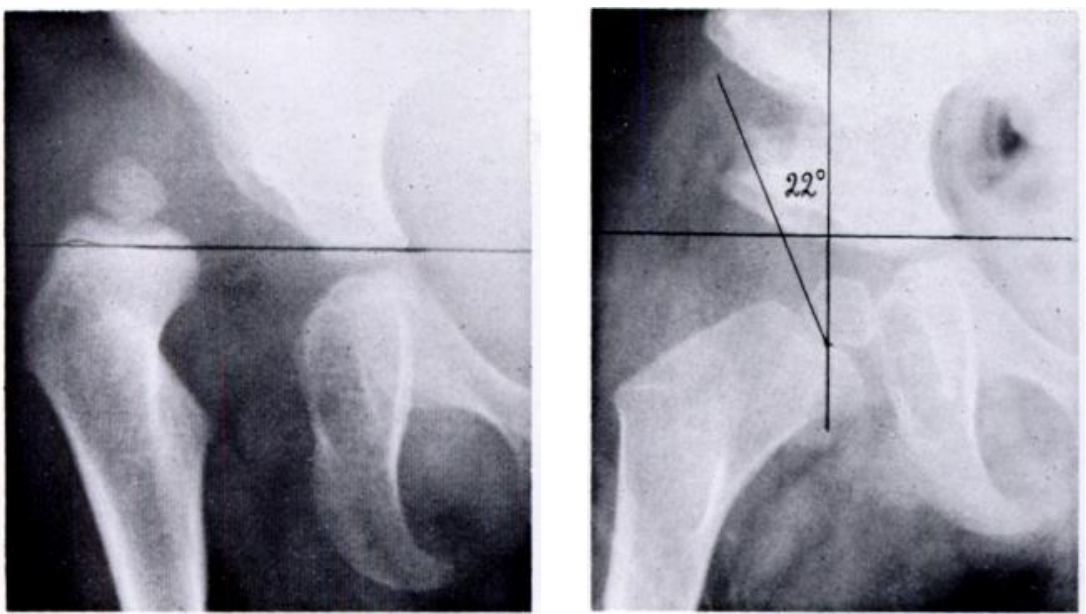

Fig. 4

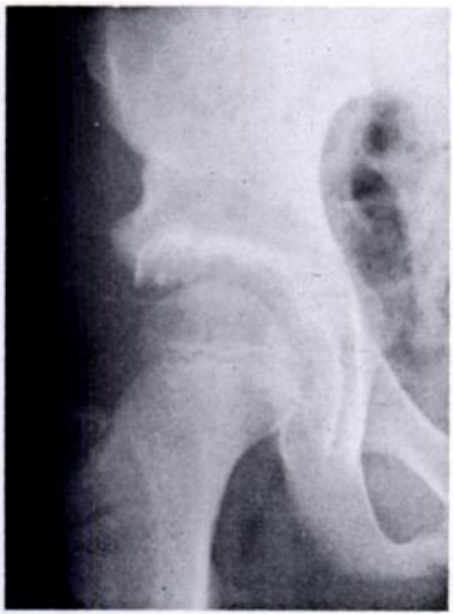

A typical early case of primary open reduction and acetabuloplasty, (left) when diagnosed at two and a half years; (centre) after operation two months later, showing the gap filled in part by the epiphysial cartilage of the wedge; and (right) at review at the age of eleven when the grading was 19 (excellent).
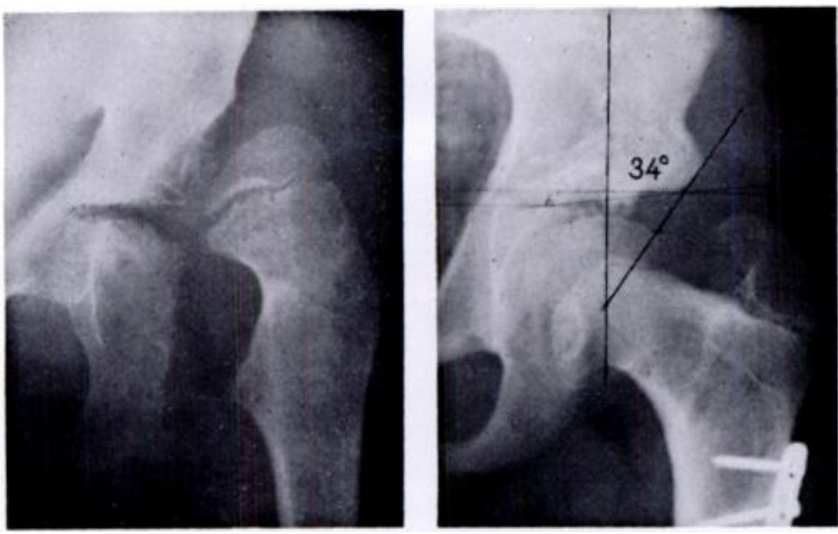

Fig. 5

A typical case of late diagnosis followed by primary open reduction and acetabuloplasty, (left $t$ at the age of five, and (right) at the age of ten, when the grading was 19 (excellent).
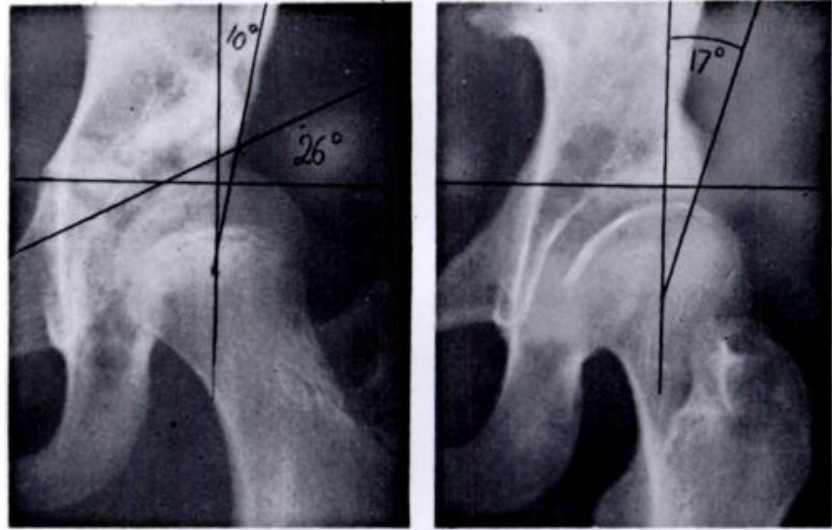

Fig. 6

Radiographs of the only case regarded as having persistent instability. Dislocation was diagnosed at two years and treated by closed reduction and rotation osteotomy. (Left) The film at ten years showing subluxation with a $C E$ angle of 10 degrees, treated by acetabuloplasty. (Right) The appearance at fifteen years, when the CE angle was 17 degrees and the grading was 17 (good). Note the rather wide joint space medially.

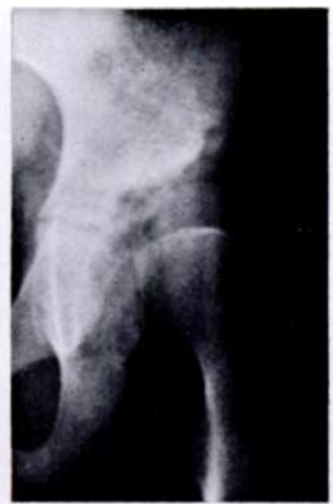

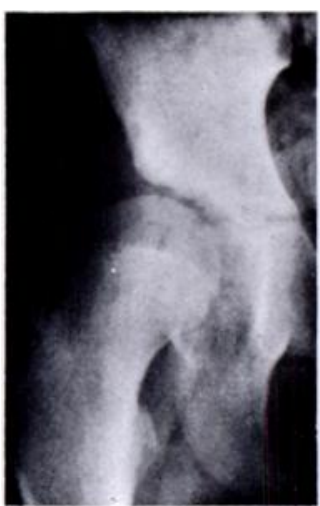

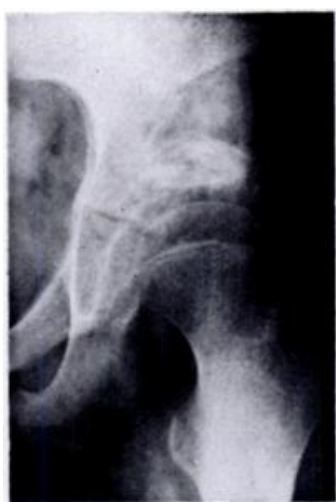

Fig. 7
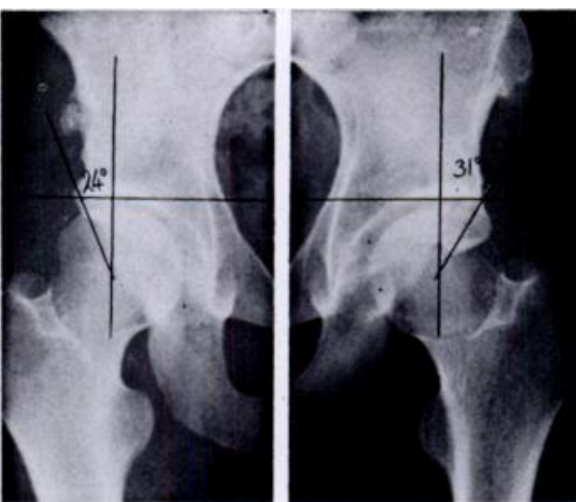

A case of subluxation diagnosed at eleven years; (left) a view taken standing (reduction was good in abduction); (centre) after acetabuloplasty of the left hip; and (right) eight years after bilateral operation, at the age of nineteen, when the grading was R-17 (good) and L-18 (excellent). 
A. L. EYRE-BROOK, D. A. JONES, F. C. HARRIS

the twelve bilateral cases had a Pemberton's operation on both sides. Of the unilateral cases, five were right hips and fourteen left. Thirty-four of the hips were in girls and only three in boys. Similar ratios were noted in a previous report from this clinic (Eyre-Brook 1968).

\section{RESULTS}

The average age at review of the various groups was: for primary open reduction and acetabuloplasty (16 hips), 8 years; for primary acetabuloplasty alone (10 hips), 11 years; and for secondary acetabuloplasty (11 hips), 14 years.

It is difficult to assess the results at these various ages but the youth of the patients favoured a high score. We adopted the excellent method of assessment of Trevor, Johns and Fixsen (1975) (Tables II and III) in

Table II. Method of assessment (Trevor, Johns and Fixsen 1975)

\begin{tabular}{|c|c|c|}
\hline Symptoms and signs & Severity & Points \\
\hline Pain & $\begin{array}{l}\text { None } \\
\text { Occasional } \\
\text { Persistent }\end{array}$ & $\begin{array}{l}3 \\
2 \\
1\end{array}$ \\
\hline Movement & $\begin{array}{l}\text { Full } \\
\text { Slight limitation but no } \\
\text { fixed deformity } \\
\text { More than half the normal } \\
\text { range } \\
\text { Less than half the normal } \\
\text { range but some fixed } \\
\text { deformity } \\
\text { Little or none }\end{array}$ & $\begin{array}{l}5 \\
4 \\
3 \\
2 \\
1\end{array}$ \\
\hline Limp & $\begin{array}{l}\text { Absent } \\
\text { Present }\end{array}$ & $\begin{array}{l}1 \\
0\end{array}$ \\
\hline $\begin{array}{l}\text { Function-as described by } \\
\text { the patient and assessed in } \\
\text { the follow-up clinic }\end{array}$ & $\begin{array}{l}\text { Full } \\
\text { Slightly limited } \\
\text { Severely limited }\end{array}$ & $\begin{array}{l}3 \\
2 \\
1\end{array}$ \\
\hline $\begin{array}{l}\text { Radiological features- } \\
\text { the } C E \text { angle of Wiberg }\end{array}$ & $\begin{array}{l}25 \text { degrees or more } \\
20-24 \text { degrees } \\
\text { Less than } 20 \text { degrees }\end{array}$ & $\begin{array}{l}3 \\
2 \\
1\end{array}$ \\
\hline $\begin{array}{l}\text { The appearance of the } \\
\text { femoral head }\end{array}$ & $\begin{array}{l}\text { Normal } \\
\text { Partial coxa plana or } \\
\text { coxa magna } \\
\text { Complete coxa plana or } \\
\text { other severe deformity }\end{array}$ & $\begin{array}{l}3 \\
2 \\
1\end{array}$ \\
\hline Shenton's line & $\begin{array}{l}\text { Intact } \\
\text { Broken }\end{array}$ & $\begin{array}{l}1 \\
0\end{array}$ \\
\hline $\begin{array}{l}\text { Evidence of degenerative } \\
\text { changes }\end{array}$ & $\begin{array}{l}\text { Absent } \\
\text { Present }\end{array}$ & $\begin{array}{l}1 \\
0\end{array}$ \\
\hline
\end{tabular}

which a score of 18 to 20 is considered excellent, 15 to 19 good, 12 to 14 fair and below 12 poor (see Figures 4 to 10).

Failure. The single poor result at the time of review came from a child in the second group who had a dysplastic femoral head with no ossific nucleus when first seen at nine months and again at three years.

The one initial failure in the third group underlines the need for maintained concentric reduction before acetabuloplasty. This was not achieved and the consequent events are shown in Figure 9. The repeat acetabuloplasty at six years of age was preceded by an open reduction, itself more a matter of excising the antero-lateral capsular pouch than of removing any obstruction to concentric siting. In order to hold the concentric reduction, two bony wedges were used to cause a twist in the iliac roof of the acetabulum. We hold that the importance of removal of capsular pouches that invite displacement has not been sufficiently stressed.

\section{Complications}

There were no deaths nor any lesion of the sciatic nerve.

Redislocation. In one case the radiograph taken immediately after operation appeared satisfactory, but on removal of the spica at six weeks the hip had redislocated. A repeat open reduction after another six weeks proved rather difficult, but at review five years later, flexion was to 100 degrees, other movements were full, and the grading was excellent (18). Since this complication all hips have been checked again radiologically two weeks after operation.

Table III. Assessment of results after Trevor, Johns and Fixsen (1975)

\begin{tabular}{|ll|lr|}
\hline $\begin{array}{l}\text { Primary open reduction and } \\
\text { acetabuloplasty }\end{array}$ & (16 hips) \\
Primary acetabuloplasty only (10 hips) & Excellent & 16 \\
& & Good & 8 \\
& Poor & 1 \\
Secondary acetabuloplasty & $(11$ hips $)$ & Excellent & 4 \\
& & Good & 4 \\
& & Fair & 1 \\
& & Poor & 1 \\
& Initial failure & 1 \\
\hline
\end{tabular}

Pelvic rotation. In one operation at twenty-one months where the descent of the acetabular roof was recorded as 2 centimetres, the radiograph obtained through the plaster showed the usual appearances, but later views revealed an element of pelvic rotation, presumably at the triradiate cartilage (Fig. 10). The radiograph six years later gave no cause for concern and the triradiate cartilage remained open. This was the only hip showing rotation within the pelvis, a feature on which Salter (1961) laid much store in his pelvic osteotomy.

Other features. In the follow-up radiographs, the triradiate cartilage was studied in all the hips but early closure or other abnormality was not seen.

There was no case of frank epiphysitis. The commonest abnormality of the femoral head was a mild coxa magna in ten cases. Coxa plana in seven cases was minimal except for two hips - one in the case of severe dysplasia already referred to; and the other after a secondary acetabuloplasty which was the third operation on the hip. Both gave poor results. 

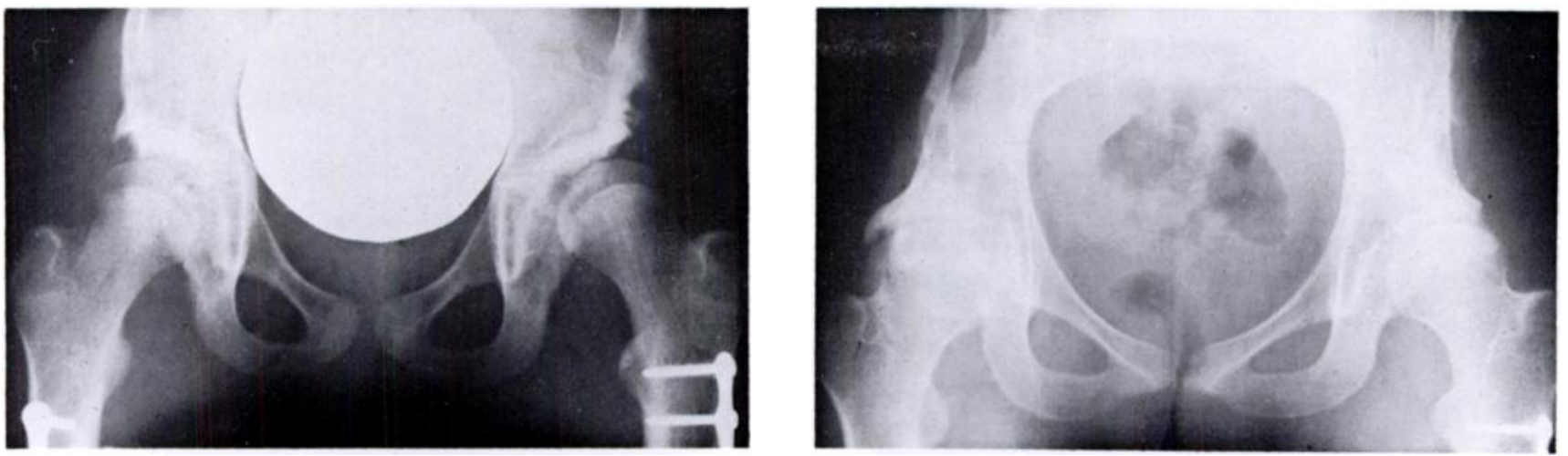

Fig. 8

Radiographs of hips treated elsewhere for bilateral dislocation by Parker's type of acetabuloplasty and rotation osteotomy. (Left) A film taken at eleven years. The film taken one year later showed an increase in subluxation, especially on the left side, and Pemberton's operation was performed on both hips. (Right) The appearances seven years later at the age of nineteen, when the grading was $R-13$ (fair) and L-16 (good).
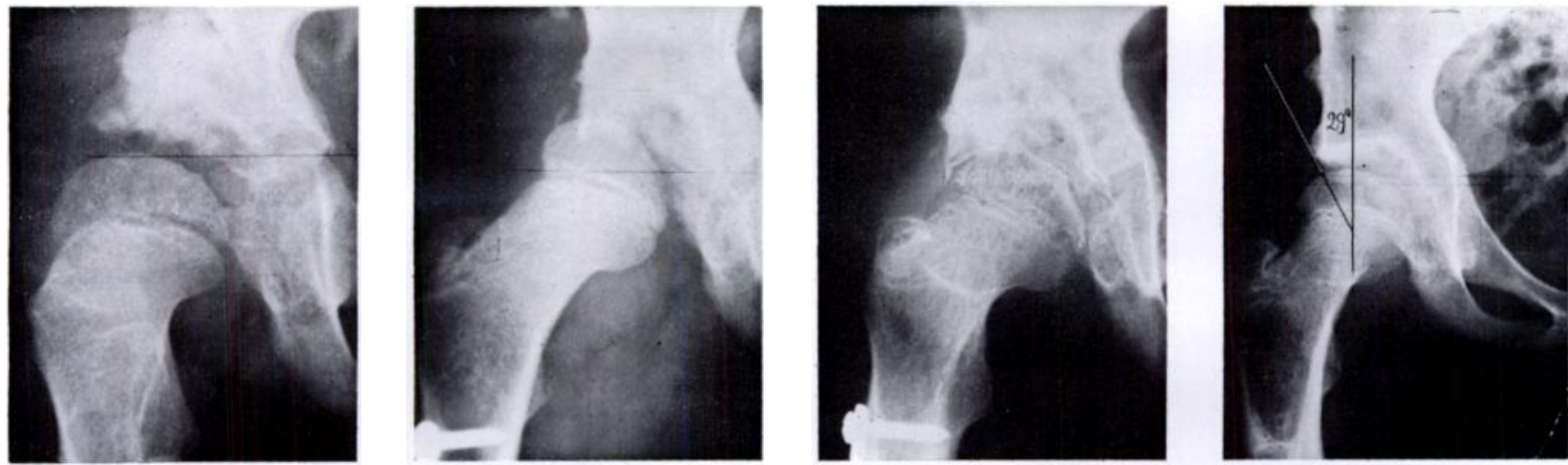

Fig. 9

A case of bilateral dislocation diagnosed at one and a half years which had been treated elsewhere by limbectomy and rotation osteotomy but had developed a recurrence of displacement on the right side. (Far left) The right hip after Pemberton's operation at four years. (Left centre) Two years later, showing a recurrence of dislocation. (Right centre) The appearance after open reduction and a second Pemberton's operation. (Far right) Three years later at the age of nine, when the result had to be graded as an initial failure, though the CE angle was 29 degrees and the final grading was 16 (good).
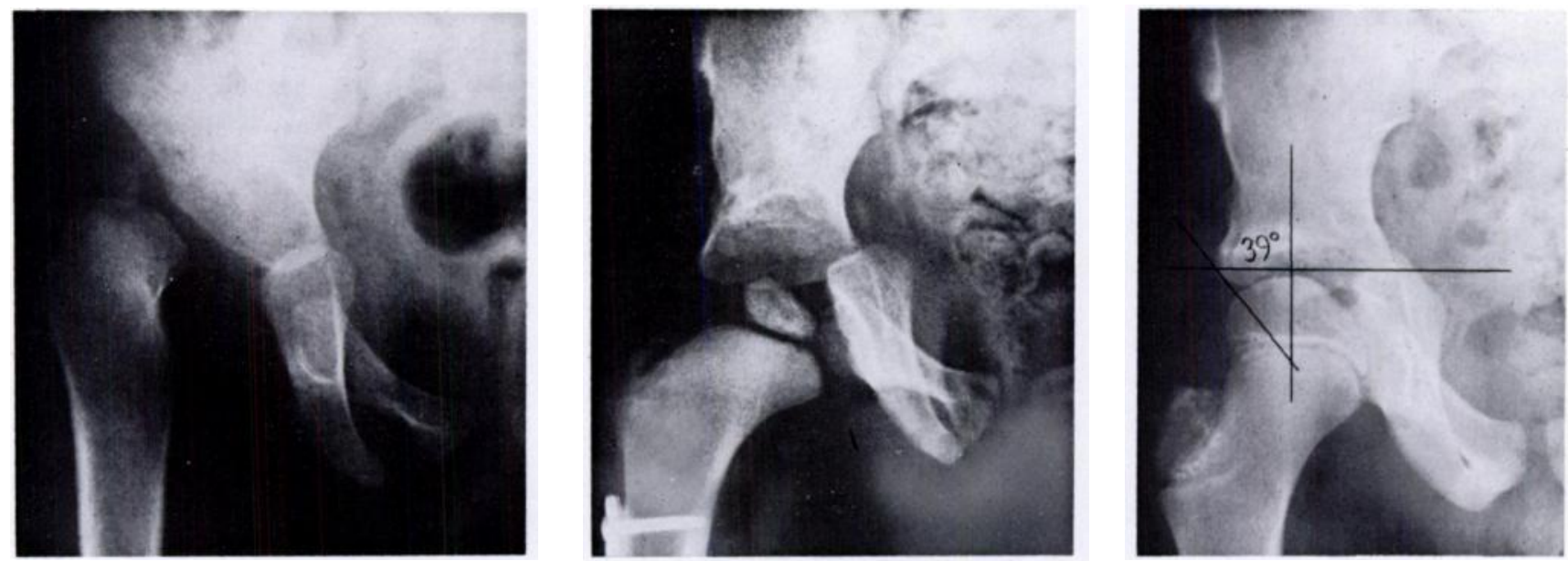

Fig. 10

Radiographs in a case of bilateral dislocation. (Left) The right hip at the time of diagnosis at one and a half years. (Centre) After treatment by open reduction. Pemberton's operation and rotation osteotomy. Rotation has occurred within the hemi-pelvis. (Right) The radiograph taken on review at the age of eight, when the grading was 20 (excellent). 


\section{DISCUSSION}

The indication for Pemberton's acetabuloplasty arises when a concentrically reduced femoral head moves, or in all probability will move, into an eccentric position due to the sloping iliac portion of a shallow acetabulum, very much as stated by Trevor, Johns and Fixsen. This definition covers the prophylactic use of acetabuloplasty, which we have employed to some extent. Pemberton has made a strong plea for the early recognition of impending failure of conservative treatment, and certainly it is a serious error to delay corrective surgery.

The policy in our unit between 1966 and 1973 was to perform an early acetabuloplasty on a hip with doubtful stability. A leaning towards open reduction frequently gave rise to a situation where a Pemberton acetabuloplasty could readily be added when the acetabulum proved to be shallow and sloping. We entirely agree with Pemberton that under the age of eighteen months the bone is too soft for his operation.

We do not agree with Pemberton, however, that one can affect the direction of descent of the acetabular roof by varying the osteotomy cuts on the medial and lateral sides of the ilium. It appears to us that the hinge, which is the fracture-separation at the triradiate cartilage, is the controlling factor and allows movement in one plane only. The dissected specimen of a normal hip (Fig. 1) illustrates well what is accomplished by this pericapsular acetabuloplasty. The head descendswhich stresses the need to incise the tight medial capsule - and becomes better covered in all directions by the acetabular roof. The latter becomes cupped over the head by some moulding in its descent, and the femoral head comes to lie beneath a broader crosssection of the iliac acetabulum, which steadily increases in width between apex and base hinged at the triradiate cartilage. The increased stability of the hip can well be tested at operation, the snap fit of the graft giving confidence in the security of the reconstruction.

A study of the specimen illustrated in Figure 1 showed that movement at the triradiate cartilage could stem from a fracture-separation either laterally into the acetabulum or medially towards the pelvis, possibly with some contribution from each. In older children with a closing or closed triradiate cartilage, we really perform a low broad pelvic osteotomy at pericapsular level, the bony wedge again being well held without any metallic fixation. In older children complete closure of the triradiate cartilage introduces features that change the whole nature of this operation; it becomes only partly an acetabuloplasty and is much less satisfactory.

We submit that the results of our experience of Pemberton's acetabuloplasty are good and that the wide access needed is fully justified. Open reduction and rotation osteotomy have certainly contributed to these results. Early intervention has become our policy.

\section{REFERENCES}

Eyre-Brook, A. L. (1968) Some aspects of congenital dysplasia of the hip. Annals of the Royal College of Surgeons of England, 43, 1-18.

Pemberton, P. A. (1965) Pericapsular osteotomy of the ilium for treatment of congenital subluxation and dislocation of the hip. Journal of Bone and Joint Surgery, 47-A, 65-86.

Salter, R. B. (1961) Innominate osteotomy in the treatment of congenital dislocation and subluxation of the hip. Journal of Bone and Joint Surgery, 43-B, 518-539.

Smith-Petersen, M. N. (1949) Approach to and exposure of the hip joint for mold arthroplasty: Journal of Bone and Joint Surgery, 31-A, 40-46.

Trevor, D., Johns, D. L., and Fixsen, J. A. (1975) Acetabuloplasty in the treatment of congenital dislocation of the hip. Journal of Bone and Joint Surgery, 57-B, 167-174. 